DOI 10.37882/2223-2982.2020.07.33

\title{
ДИАГНОСТИКА ФОРМИРОВАНИЯ ИНФОРМАЦИОННО-АНАЛИТИЧЕСКОЙ КУЛЬТУРЫ
}

\section{DIAGNOSTIC FORMATION OF INFORMATION ANALYTICAL CULTURE \\ E. Fedotova}

Summary: The article actualizes the problems of the formation of information and analytical culture as the basis of the general culture of a professional economic profile. The author considers this problem from the perspective of finding ways to determine diagnostic tools for indicators of the formation of the information-analytical culture of students in economic areas. Objective: to develop a system of tasks for diagnosing the formation of an information-analytical culture based on accounting for the components of an information-analytical culture and the criteria for its formation. Subject: diagnostics of the formation of information and analytical culture of students in economic areas. The following methods were used in the article: synthesis-isolation of structures, generalization, analysis, search and research, descriptive. Novelty: the work proposes a system of tasks for checking indicators of the criteria for the formation of information and analytical culture of students; business cases have been developed that reflect the possibility of diagnosing the formation of an information-analytical culture in the framework of creating a professional portfolio. Results: the article identifies the main components of the information-analytical culture; presented developed criteria for the formation on the basis of identified components; tasks for evaluating each criterion are developed; business cases have been developed for the final assessment of the formation of students' information-analytical culture, which allow evaluating the performance of all criteria. Scope of the results: the field of training information and analytical activities for all sectors of the economy, practical areas (production, practical medicine, etc.).

Keywords: information and analytical culture, formation diagnostics, task development for checking criteria indicators, business case, professional portfolio.
Федотова Елена Андреевна

Аспирант, ГБОУ ВО Московской области «Технологический университет", г. Королев ktf16@yandex.ru

Аннотация: В статье актуализируется проблематика формирования информационно-аналитической культуры как основы общей культуры профессионала экономического профиля. Автор рассматривает данную проблему с позиций поиска путей определения средств диагностики показателей сформированности информационно-аналитической культуры обучающихся экономических направлений. Цель работы: разработка системы заданий для диагностики формирования информационно-аналитической культуры на основе учета составляющих информационно-аналитической культуры и критериев ее сформированности. Предмет: диагностика формирования информационно-аналитической культуры обучающихся экономических направлений. В статье использованы следующие методы: синтез-вычленения структур, обобщения, анализа, поисково-исследовательский, описательный. Новизна: в работе предложена система заданий для проверки показателей критериев формирования информационно-аналитической культуры обучающихся; разработаны бизнес-кейсы, отражающие возможность диагностики формирования информационно-аналитической культуры в рамках создания профессионального портфолио. Результаты: в статье выявлены основные компоненты информационно-аналитической культуры; представленные разработанные критерии формирования на основе выявленных компонентов; разработаны задания для оценки каждого критерия; разработаны бизнес-кейсы для итоговой оценки сформированности информационно-аналитической культуры обучающихся, позволяющих оценить показатели всех критериев. Область применения результатов: сфера обучения информационно-аналитической деятельности для всех секторов экономики, практических областей (производство, практическая медицина и др.).

Ключевые слова: информационно-аналитическая культура, диагностика формирования, разработка заданий для проверки показателей критериев, бизнес-кейс, профессиональное портфолио.

формационном многообразии [1; 3].

Многоаспектность информации и ее растущие объемы в условиях реального социально-экономического развития обусловливают такой подход к ее дифференциации и обработки, при котором одним из условий устойчивого развития становится актуализация деятельностных форм, представляющих основу аналитического подхода оперирования информацией. К таким деятельностным формам относят информационно-аналитическую деятельность, опосредующую формирование информационно-аналитической культуры, которая обеспечивает успешность решений в различных областях $[5 ; 8 ; 9 ; 11]$. 
Одной из основных составляющих информационноаналитической культуры является фактор значимости информации, оцениваемой не просто с позиций ее наличия для конкретной решаемой задачи, а с позиций ее достаточного уровня достоверности для определения успешности решения, а также ее качества, определяющего социальную значимость. Данный аспект определяет ценностно-смысловой компонент информационно-аналитической культуры, обеспечивающий формирование ценностных ориентаций в отношении выбираемой профессии (экономиста, аналитика и т.п.), осознание социальной значимости информационноаналитической деятельности, понимание роли культурных основ формирования социального блага как категории социальной защищенности и т.п. [7; 10].

Эта ценностная составляющая заложена в основе одного из основных критериев сформированности информационно-аналитической культуры будущего специалиста, а именно, ценностно-прогностический, заключающийся в способности и готовности к анализу, оценке, интерпретации полученных результатов, определяющих обоснование экономических выводов.
Проверка сформированности показателей каждого из критериев (а их в статье мы рассмотрим четыре, акцентируя внимание на них как на основных аспектах, отражающих концепты структурных составляющих информационно-аналитической культуры) в процессе диагностики формирования информационно-аналитической культуры осуществляется, конечно же, на основе соответствующих заданий, качество выполнения которых констатирует динамику ее [культуры] развития.

Так, например, для проверки вышеуказанного критерия обучающимся можно предложить следующее задание:

Произвести анализ динамики и структуры основных производственных фондов предприятия на основании данных, приведенных в табличе 1.

Обосновать, для какой цели может служить анализ этих данных.

Следующим важным компонентом информационноаналитической культуры является ее операциональный

Таблица 1

Динамика и структура основных производственных фондов предприятия

\begin{tabular}{|l|c|c|c|c|c|c|}
\hline \multirow{2}{*}{ Группы основных фондов } & \multicolumn{2}{|c|}{2018} & \multicolumn{2}{c|}{ Отклонение } \\
\cline { 2 - 7 } & Тысяч. Руб. & Удельный вес, \% & Тысяч. Руб. & Удельный вес, \% & Тысяч. Руб. & Удельный вес, \% \\
\hline $\begin{array}{l}\text { Всего общих производ- } \\
\text { ственных фондов }\end{array}$ & 2735053 & 100 & 3857832 & 100 & 1122779 & 141,1 \\
\hline Здания & 13226 & 0,48 & 27880 & 0,72 & 14654 & 0,24 \\
\hline Соружения & 82890 & 3,03 & 88235 & 2,29 & 5345 & $-0,74$ \\
\hline Оборудование & 1234505 & 45,14 & 1870216 & 48,48 & 635711 & 3,34 \\
\hline Ср-ва транспортн. & 1401421 & 51,24 & 1864272 & 48,32 & 462851 & $-2,92$ \\
\hline Инвентарь & 3011 & 0,11 & 7229 & 0,19 & 4218 & 0,08 \\
\hline Активы & 2638937 & 96,5 & 3741717 & 97,0 & 1102780 & 0,5 \\
\hline
\end{tabular}

Показатели движения по группам основных производственных фондов

\begin{tabular}{|c|c|c|c|c|}
\hline \multirow{2}{*}{ Группы основных фондов производства } & \multicolumn{4}{|c|}{ Коэффициенты } \\
\hline & ввода & выбытия & прироста & компенсации \\
\hline Всего основных производственных фондов & 36,45 & 10,36 & 4,94 & 496,18 \\
\hline Здания & 52,56 & & 110,79 & \\
\hline Сооружения & 6,06 & & 6,45 & \\
\hline Оборудование & 40,83 & 10,36 & 51,5 & 596,93 \\
\hline Средства транспортн. & 33,15 & 11,07 & 33,03 & 398,29 \\
\hline Инвентарь & 62,62 & 10,26 & 140,09 & 1465,05 \\
\hline Инвентарь & 62,62 & 10,26 & 140,09 & 1465,05 \\
\hline
\end{tabular}


понятийный аппарат, составляющий теоретико-методологические основы реализации процессуально-деятельностного критерия. Данный критерий заключается в способности ориентироваться в основных понятиях, методах, способах, обусловливающих продуктивный поиск необходимой информации, определенный характеристиками аналитической задачи, а также сбор, обработку, анализ данных и их хранение.

Для проверки показателей этого критерия можно использовать следующее задание:

В рамках задания ознакомиться с понятиями: коэффичиент ввода, движение по группам основных производственных фондов, коэффичиент (выбытия, прироста, компенсации).

Проанализировать данные из таблицы 2:

Исходя из анализа данных, ответить на вопросы:

- Достаточно или недостаточно происходит обновление основных производственных фондов?

- Изношены ли объекты на предприятиях?

- Какие объекты производственных фондов обновляются наиболее интенсивно?

- за счет чего происходит расиирение производства и увеличение масштабов деятельности данного предприятия?

- Какие позиции можно охарактеризовать как позиции значительного износа?

Дальнейшая методология работы с данными: разработайте «дерево» хранения основной информации по производственным фондам, используя теги «анализ», «период», «динамика», «исходные данные», «показатели движения». Данные располагайте в табличном виде.

Необходимо отметить, что, формируя фонд заданий для проверки сформированности показателей критериев, можно планировать создание бизнес-кейсов в рамках реализации проектного метода Case study. Задания могут быть подэтапами решения как одной наиболее объемной профессионально-ориентированной ситуации, так и быть отдельными самостоятельными задачами. Проверяя показатели критериев сформированности информационно-аналитической культуры обучающихся в контексте одного многоэтапного бизнес-кейса, можно говорить о реализации в образовательном процессе профессионально-контекстной поисково-исследовательской технологии. Такие бизнес-кейсы могут рассматриваться как профессиональные портфолио. Если же в рамках бизнес-кейса обучающие смогут предложить программируемые варианты каких-либо решений (операции с данными, хранение данных и пр.), то можно говорить об актуализации в их деятельности такого компонента информационно-аналитической культуры как способность использовать компьютерные приложения, программное обеспечение для обработки информации, работы с ней, осуществлять прогнозирование экономических выводов (используя построение регрессий, линий тренда, математические функции и пр.).

Так, например, проверка показателей критерия (основанного на сущности вышеизложенной составляющей информационно-аналитической культуры), заключающегося в развитии способностей обучающихся включаться в процесс достижения соответствия скорости поступательного увеличения объемов необходимой для анализа информации, а также владением прогрессивной методологии ее поиска, может быть осуществлена с помощью следующего задания:

Имея данные деятельности предприятия, выраженные в коэффичиентах ввода, проанализируйте динамику обновления и износа в группе основных производственных фондов на основе знаний работы с массивами (определенными структурами данных, в которых можно хранить множество значений):

Эman 1. Отсортируйте по возрастанию целочисленный массив из п элементов, используя цикл for и условную конструкцию if.

Эman 2. Выведите отсортированный массив из предыдущей задачи в консоль, используя цикл for.

В контексте данного задания скорость работы с данными, используемыми для аналитической деятельности, обусловливается умениями и навыками основ программирования, что говорит о более высоком уровне сформированности информационно-аналитической культуры в рамках технологического обеспечения информационно-аналитической деятельности и готовности обучающегося к построению модели сравнительного ресурсного анализа [4].

Говоря о составляющей, связанной с вычислением основных экономических понятий [2;6], необходимо обратить внимание на то, что данный компонент информационно-аналитической культуры отражен в таком критерии ее [культуры] сформированности как способность обучающихся на основе данных понятий осуществлять проведение аналитических расчетов экономических и сочиально-экономических показателей на основе типовых методик с учетом критериев действующей нормативно-правовой базы и локальных актов. Так, например, в процессе диагностики показателей данного критерия можно предложить обучающимся расчет ресурсного потенциала предприятия, который в рамках единичной самостоятельной задачи может заключаться в расчетах, относящихся к первому этапу - расчету единичных показателей критериев оценки ресурсного потенциала (конкретного предприятия, можно регионального): 
- уровень организации предприятия или коэффиицент специализации;

- уровень технической базы предприятия или коэффициент (обновления, выбытия, износа);

- эффективность производственной деятельности (производительность труда, рентабельность товара и т.n.).

Оформив все задания по диагностике показателей каждого критерия в одно направление по одному или нескольким связанным предприятиям, можно сформировать портфолио-ориентированный бизнес-кейс.

\section{Hanример:}

а) стратегчческий кейс;

Имея сводный рейтинг ресурсного потенциала четы$\operatorname{pex}(A, B, C, D)$ предприятий, составить прогноз рейтинга ресурсного потенциала после проведения слияния (поглощения):

I эman. Анализ основных производственных фондов предприятий, расчет единичных показателей критериев ресурсного потенциала (уровень организации производства, уровень технической базы, эффективность производственной деятельности; оценка рыночной устойчивости, деловой активности, социального уровня).

I/ эman. Расчет критериев ресурсного потенциала (производится расчет всех критериев в соответствии с данными анализа для I этапа).

III эman. Расчет общего рейтинга предприятий. Прогноз эффективности слияния (поглощения). Презентация.

б) кейс, касающийся организации, технологий и прочессов на производстве;

Определение устойчивости развития предприятия н основе оценки медико-биологического фактора обеспечения надежности кадрового потенциала:

I эman. Сбор информации об индикаторах и показателях процессов. Проверка информации на достоверность и объективность. Системный анализ полученной информации, ее оценка. Сортировка данных, распределение данных для хранения.

I/ эman. Расчет надежности кадрового потенциала пу- тем построения модели биологических отказов. Модель биологических отказов необходимо выстраивать путем изучения данных заболеваемости кадров, например, за годовой период: так, например, если уровень нетрудоспособности по причине заболеваемости в пересчете на тысячу работников составляет 7000 дней, то число отказов на 1 работника в месяц будет варьироваться в пределах 0,6 или 0, 02 отказа в сутки (0, 0008 в 1 час).

III эman. Расчет приращения параметров с учетом данных полученных на этапах I и II (продолжительность рабочего времени, число отказов по причине заболеваний, число отказов по причине переутомления и пр.).

Для расчета ошибок, совершаемых кадрами в процессе трудовой деятельности использовать формулу:

$$
\mathrm{N}=\frac{t-8}{1000000}
$$

Для расчета надежности кадрового фактора в производственной системе:

$$
B=e-(03+0 \Pi) t
$$

IV эman. Построение модели мониторинга. Прогнозирование репрезентирующих факторов. Формирование информационно-аналитической базы мониторинга.

Решение бизнес-кейсов, характер и технологическое исполнение которых может носить стратегический, операциональный, финансовый, технологический, модельно-мониторинговый и др. характер, позволяет диагностировать уровень информационно-аналитической культуры его [кейса] исполнителя. Поэтапное выполнение заданий, которые являются и автономными, и одновременно, составными подзадачами целостной ситуативной проблемы, позволяет обучающимся демонстрировать умения работы с информацией, навыки управления информацией, а также важные надпрофессиональные (интегрированные предметные) навыки, обеспечивающие успешность работы в команде с целью боле высокой эффективности рабочего процесса, и глубокие профессиональные навыки, демонстрируемые на уровне профессионального информационно-аналитического портфолио с конкретными бизнес-решениями.

\section{ЛИТЕРАТУРА}

1. Галущенко, О.В. Информационно-аналитическая деятельность и коммуникации / О.В. Галущенко // Известия высших учебных заведений. Северо-Кавказский регион. Общественные науки. - 2010. - № 4. - С. 5-8.

2. Курносов, Ю.В. Аналитика. Методология, технология и организация информационно-аналитической работы / Ю.В. Курносов, П.Ю. Курносов. - Москва: Издательство «Русаки», 2004. - 550 c.

3. Курныкина, О.В. Проблемы и развитие информационно-аналитического обеспечения банковской деятельности / 0.В. Курныкина // Финансы и кредит. 2017. - № 5. - С. 250-258.

4. Подчернин, В.М. Некоторые вопросы информационного обеспечения и информационно-аналитической деятельности / В.М. Подчернин // Библиосфера. 
- 2007. - № 1. - C. 21-32.

5. Романова, Ю.В. Роль информационно-аналитического обеспечения учета товаров в деятельности предприятий розничной торговли / Ю.В. Романова // Учет, анализ и аудит: проблемы теории и практики. - 2017. - № 18. - С. 146-150.

6. Седова, И.В. Сущность информационно-аналитической культуры будущих бакалавров экономики / И. В. Седова // Человеческий капитал. - 2012. - № 5 (41). - C. 145-148.

7. Свердлина, Е.Б. Компетентностный подход в аналитической подготовке бакалавров экономики: проблемы и пути их решения / Е.Б. Свердлина, А.Ю. Яковлева // Вестник Омского университета. Серия «Экономика». - 2018. - № 3. - С. 149-163.

8. Тажигулова, Г.О. Формирование основ аналитической культуры будущих специалистов транспортно-дорожного профиля [Электронный ресурс] / Г.0. Тажигулова // Вестник КарГУ. - 2014. - Режим доступа: https://articlekz.com/article/11192

9. Темерова, Н.И. Информационно-аналитическая деятельность в информационном пространстве [Электронный ресурс] / Н.И. Темерова. - Режим доступа: http://elib.sfu-kras.ru/handle/2311/5448

10. Тироль, Жан. Глобальные задачи, профессия экономиста и общее благо / Жан Тироль // Финансы: Теория и Практика. - 2019. - № 1. - С. 6-12.

11. Фисаков, М.Ю. Информационно-аналитическая деятельность следственных органов / М.Ю. Фисаков // Юристъ-Правоведъ. - 2018. - № 3. - С. 124-129.

() Федотова Елена Андреевна (ktf16@yandex.ru).

Журнал «Современная наука: актуальные проблемы теории и практики»

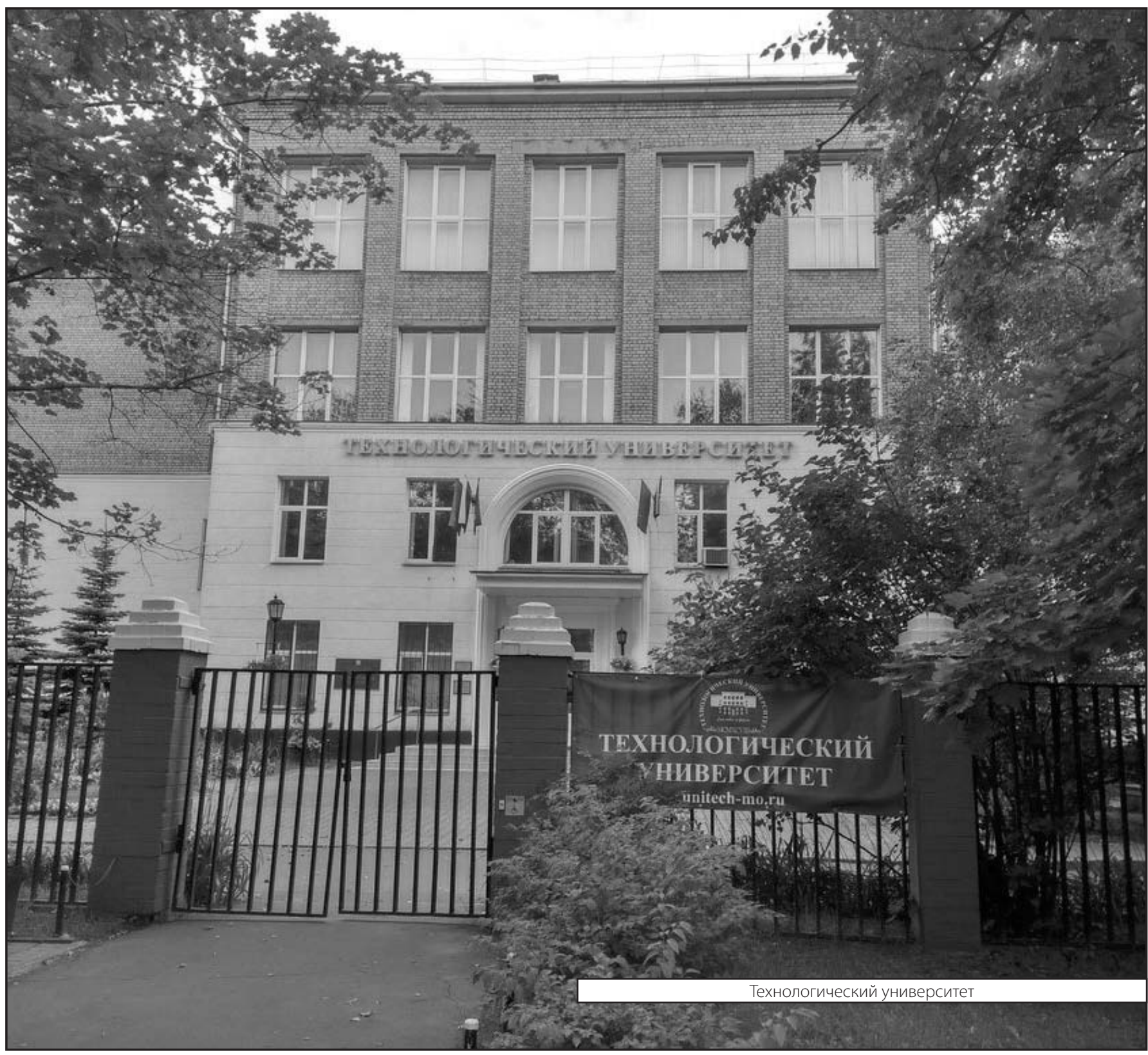

